\title{
Escuchar, recolectar, configurar: inscripciones de la poesía popular en Juan Alfonso Carrizo y Bernardo Canal Feijóo
}

\author{
Diego Bentivegna \\ CONICET \\ Universidad Nacional de Tres de Febrero \\ Universidad de Buenos Aires
}

\begin{abstract}
Resumen
En este artículo se analizan las tensiones en torno al proyecto de construcción del acervo de la poesía popular en la Argentina de los años 30 y 40. Nos centramos para ello en la serie de cancioneros más importantes publicados en el país durante ese período -los correspondientes a las provincias del noroeste, compilados por Juan A. Carrizo, publicados entre 1926 y 1942- y los ensayos sobre temática folklórica publicados en ese mismo lapso por el intelectual santiagueño Bernardo Canal Feijóo. Teniendo en cuenta dicho corpus, nos detendremos en el modo en que ambos autores abordan el problema de la voz del otro, de su escucha y de su transcripción. En este punto, reflexionamos sobre el problema de la escucha y de la puesta en escritura a partir de la categoría de vocalidad propuesta por Paul Zumthor y a partir de la categoría teórica de archivo, tal como es elaborada fundamentalmente por Paul Ricoeur y por Jacques Derrida. Nos detenemos, a partir de ello, en las implicancias político-culturales de las operaciones de archivo llevadas adelante por ambos autores, en función de los debates en torno a los componentes hegemónicos de aquello que se piensa como cultura popular legítima en la Argentina.
\end{abstract}

Palabras clave: poesía tradicional; poesía popular; vocalidad; heteroglosia; folklore literario.

\section{Summary}

This article discusses the tensions regarding the construction project of the heritage of folk poetry in Argentina in the 30s and 40s. We focus on the series of most important songbooks published in the country during that period: the corresponding to the provinces in the Northwest, compiled by John A. Carrizo, published between 1926 and 1942, and the thematic essays on folk published in that same period by the Santiago del Estero intellectual Bernardo Canal Feijóo. Taking into account the corpus, we stop at the way in which both authors address the issue of voice of the other, of their listening and transcription. At this point, we reflect on the problem of listening and of the implementation in writing from the categories on the oral poetry proposed by Paul Zumthor and from the category of archive, as it is developed mainly by Paul Ricoeur and Jacques Derrida. We pause, on this basis, in the political-cultural implications of the archive operations taken forward by both authors, according to the debates concerning the hegemonic components of what it is thought like legitimate popular culture in the Argentina.

Key Words: traditional poetry; popular poetry; oral poetry; heteroglossia; literary folklore. 
1. CASANOVA, Pascale. $\mathrm{La}$ república mundial de las letras, 2001, p. 293 y ss.

2. ROMANO, Eduardo. Intelectuales, escritores e industria cultural, 2012.

3. Ver SARLO, Beatriz. Una modernidad periférica. Buenos Aires, 1920-1930, 2003; ROMANO, Eduardo. Sobre poesía popular argentina1983 y, del mismo autor, ROMANO, Eduardo. Intelectuales, escritores e industria cultural, 2012.

\section{La folklorología argentina: un proyecto}

Entre las décadas del 20 y del 40 del siglo XX se publican en la Argentina un número considerable de textos, en muchos cansos de dimensiones monumentales, que se proponen recoger, exhibir y preservar el acervo poético de la nación. Se trata de una serie de textos que se articula tanto con el saber filológico o literario como con el saber de carácter antropológico, que desembocará en la consolidación de un área epistemológica concreta: la de la folklorología. En la confluencia de dos universos teóricos, el filológico y la folklorológico, se plantea la construcción discursiva de una entidad colectiva, el pueblo, como una de las instancias en las que se va a dirimir, en la herencia del romanticismo de Johann Herder, la afirmación de una determinada legitimación literaria de los estados nacionales contemporáneos. ${ }^{1}$

La labor de los folklorólogos argentinos durante la primera mitad del siglo XX exhibe varias facetas en las que lo popular aparece como objeto de una disputa con implicancias políticas evidentes. Se trata de un trabajo que se fundamenta, en general, en una concepción planteada ya a comienzos del proceso de modernización argentina por algunos miembros de la elite intelectual, que, como Calixto Oyuela, Miguel Cané y Ernesto Quesada, contraponían el campesino iletrado de las provincias históricas argentinas a las clases populares urbanas, que veían como el producto híbrido de nativos e inmigrantes y que eran portadoras de una serie de prácticas culturales percibidas como plebeyas y peligrosas. $^{2}$ En este esquema, la reivindicación de las raíces hispánicas y la crítica conjunta al nacionalismo cultural, es decir, a la opción representada por intelectuales del interior como Leopoldo Lugones y, con más ahínco todavía, por Ricardo Rojas, comienza a jugar un papel decisivo en la disputa por la configuración hegemónica de lo que se considera popular.

Los más importantes cancioneros de la época que en la Argentina se abre con el ascenso del radicalismo en 1916, la consolidación de la democracia de masas y el desarrollo de la industria cultural ${ }^{3}$ fueron, sin duda, los recopilados y anotados por Juan Alfonso Carrizo. Nacido en 1895 en una localidad rural de la provincia de Catamarca, por entonces una de las zonas menos desarrolladas del noroeste del país, Carrizo inició la publicación de la serie de cancioneros en 1926, con un volumen dedicado a su provincia natal. En los años sucesivos, Carrizo, en el marco de su proyecto totalizante de recolección del acervo, publicará sustanciosos volúmenes dedicados a las diferentes provincias del noroeste, que constituían la antigua 
administración colonial del Tucumán: Salta (1933), Jujuy (1935), Tucumán (1937, en dos volúmenes) y, finalmente, La Rioja (1942, en tres volúmenes).

El problema de la voz, las tensiones entre la escucha de los sujetos investidos de las prerrogativas de ese patrimonio y la puesta en escrito de esos materiales, constituye una zona en la que se despliegan una serie de cuestiones que afectan la elaboración de una concepción de poesía popular legítima. La configuración de las compilaciones de poesía popular, que con el tiempo - por las tensiones que presenta el concepto - preferirán denominarse con el término "tradicional”, representan uno de los lugares de configuración hegemónica del archivo, entendido, según los planteos de Paul Ricoeur (2004), como la zona del pasaje de la oralidad a la escritura, lo cual supone la conformación del testimonio (oral) en texto escrito, depositable, archivable y clasificable.

Por un lado, a partir del impulso de Carrizo se intenta recoger y sistematizar el conjunto del acervo poético popular considerado legítimo, como parte de un proyecto de reconfiguración general de la cultura y de la sociedad argentina en la que los políticos e intelectuales del interior del país juegan un rol esencial. No hay que olvidar, en efecto, que la actividad de Carrizo y de sus alumnos - Bruno Jacovella, Rafael Jijena Sánchez, etc. - se sostiene desde el punto de vista material, pero también desde el punto de vista ideológico, en el accionar de figuras claves del entramado político y económico tucumano, como el filósofo y hacendado Alberto Rougès, el ex gobernador Ernesto Padilla y el rector de la Universidad Nacional de Tucumán, Juan B. Terán. ${ }^{4}$ En este sentido, la obsesión por la pureza de los materiales, que se exhiben en los cancioneros como objetos incontaminados en relación con influencias externas, se considerará un punto fundamental. Por otro lado, se despliegan sobre esos materiales, desde el momento mismo de su presentación en los grandes cancioneros, una serie de hipótesis interpretativas que conducirán a la publicación en el año 1945 de un libro de dimensiones monumentales: los Antecedentes hispano-medievales de la poesía tradicional argentina.

El imponente volumen - de más de seiscientas páginas exhibe una nutridísima bibliografía crítica en la que Carrizo despliega toda su erudición histórica y filológica y cuenta con una introducción afectuosa de uno de los intelectuales más ligados con la cultura oficial de la España de Franco, el poeta y dramaturgo José María Pemán. Los Antecedentes se presentan como la coronación de una serie de gestos interpretativos que tienden de manera programática a manifestar la pertenencia del acervo a un patrimonio literario común a la América hispana en su conjunto, compartido por supuesto con España. En este sentido, la pertenencia al "dispositivo hispanista" que
4. Ver CHEIN, Diego.

"Provincianos y porteños..." 2010; CHAMOSA, Oscar. Breve historia del folklore argentino (1920-1970), 2012. 
5. TERÁN, Oscar. "El

dispositivo hispanista", 1993.

6. El proyecto, en sus diferentes aristas, se sintetiza en una frase del rector Juan B. Terán, citada por Berta Elena Vidal de Battini en un artículo que publica en El monitor de la educación común, el órgano del Consejo Nacional de Educación, en 1932, acerca de la necesidad de implementar la enseñanza folklórica en la escuela primaria: "No tenemos monumentos, restos materiales, ruinas que ayuden a la evocación de nuestro pasado. Nada puede reemplazar, entre nosotros, mejor que el folklore esta ausencia, para lograr la suscitación, por un estímulo penetrante de la evocación histórica" (citado en VIDAL DE BATTINI, Berta Elena, "El folklore en la escuela”, 1932, p. 20).

7. ZUMTHOR, Paul. Escritura e nomadismo, 2005, p. 17.

8. BENTIVEGNA, "El canto y la letra: disputas en torno a lo tradicional en Juan A. Carrizo y Ricardo Rojas”, 2013b.

9. MAINGUENEAU, Dominique. Discurso literário, 2009. comienza a articularse a comienzos del siglo XX es evidente. ${ }^{5}$ Se plantearán así las articulaciones de difusión de los materiales a partir de un conjunto de artículos de difusión publicados en diferentes medios de alcance nacional (desde Criterio, el principal revista cultural y política de ámbito católico, hasta medios manifiestamente nacionalistas, como los diarios El pueblo y Cabildo) y, sobre todo, a través del sistema educativo. ${ }^{6}$

Paul Zumthor, el gran medievalista suizo y uno de los principales teóricos de lo oral, afirma en una entrevista que la voz "emana de um corpo, não somente no sentido psicofisiológico do termo, mas igualmente no sentido (que, para mim, não é metafórico) em que falamos do corpo sociaP'. ' La escucha de la voz del otro nos ubica en una relación con un cuerpo - con sus entonaciones, sus gestos y sus pulsiones - que es, al mismo tiempo, el lugar donde se pone en juego una forma de vida comunitaria. Las construcciones discursivas sobre esas voces, construcciones que se orientan a captarla, reescribirla e investirla de sentido, pueden ser vistas como instancias en las que se pone en funcionamiento el modo en que los sectores letrados dan forma a una comunidad imaginada de pertenencia, que asume el aspecto de una literatura y una tradición nacionales.

Estamos ante un proyecto que se concibe a sí mismo como el rastreo, la recolección y la sistematización de la totalidad del acervo poético popular existente en las regiones visitadas. En efecto, a partir de la publicación del segundo de la serie de cancioneros, el dedicado a la provincia de Salta, Carrizo concebirá sus volúmenes como recopilaciones exhaustivas que agotan el acervo poético recogido en las regiones que él mismo recorre, a menudo, como se encarga de exhibir con insistencia en sus extensas introducciones, en condiciones de circulación y de convivencia con el pueblo que lo nutre harto dificultosas. Se trata, como hemos insistido en otros trabajos, ${ }^{8}$ de intervenciones que se conciben como "discursos instituyentes", que asumen como propio lo que puede denominarse como el establecimiento de un archeion, de un archivo y - al mismo tiempo - de una comunidad. Y esto, como afirma Jacques Derrida (1994), en un doble sentido: como depósito, como lugar en el que se clausura lo que una sociedad concibe como corpus textual conservable, pero también como ejercicio de una potestad, de un poder, ligado con la conformación de una comunidad y con la construcción de un Estado, con las disputas por el sentido de la pertenencia a un colectivo nacional y regional que esos procesos conllevan.

La estrategia de cooptación letrada de Carrizo, en relación con los cantores populares, es inseparable del marco ideológico - expresamente político - de sus intervenciones, caracterizado según Bruno Jacovella (1963), su discípulo y biógrafo, por un fuerte hispanismo, por la doble oposición al indigenismo que 
veía en la herencia aborigen el componente constitutivo de la nacionalidad, y el gauchismo, que postulaba al habitante de la región pampeana como arquetipo de lo argentino. En este sentido, la noción de poesía "popular" es para Carrizo irreductible a la de poesía "nacional", en tensión con el nacionalismo de matriz culturalista que, desde un lugar institucional muy influyente esgrimía uno de los principales blancos de las críticas de Carrizo: Ricardo Rojas, profesor de Literatura Argentina y director del Instituto de investigaciones de esa área de la Facultad de Filosofía y Letras de la Universidad de Buenos Aires. ${ }^{10}$

\section{Tensiones no resueltas. Lo seriado y lo único, lo oral y lo escrito.}

Es importante relevar las series de sentido que se entrecruzan, muchas veces en una tensión no resuelta, en el proceso de búsqueda y de recolección de los cantos populares tal como éste es reconstruido por Carrizo en los prólogos a los diferentes cancioneros. La busca se presenta, en todos los casos, como dificultosa, ya que en apariencia son pocos los sujetos que estarían en condiciones de actualizar el acervo popular.

Un aspecto sustancial para pensar el problema de la voz y de la escucha en estas recopilaciones es la tensión entre diferentes formas que asume lo que se denomina "cultura popular". En efecto, frente a las formas de transmisión artesanal ligadas fundamentalmente con la oralidad, que son las que Carrizo entiende como las formas auténticas de lo popular, se perciben en los prólogos otros fenómenos, que asumen la forma de producción seriada. Leemos al respecto en el Cancionero popular de Salta:

En la ciudad y en las villas importantes, la tarea fué relativamente fácil, porque la gente comprendía mi misión y me ayudaba, pero en los lugares serranos tuve que acompañarme con los compradores de cueros y los comerciantes ambulantes para hacer mi cosecha de coplas. A estos paisanos les decía que antes fui comprador de cueros, pero como el negocio iba mal, me dediqué a la compra de cantos para venderlos a las fábricas de caramelos; les pagaba diez centavos por copla que yo no sabía.

Efectivamente, hasta hace diez años en Catamarca, Tucumán, Salta y Jujuy se vendía en los almacenes de las ciudades y en las pulperías de la campaña unos caramelos en forma de ajíes que tenían a manera de pedúnculos un papelito arrollado, en el cual había escrita una copla.

Parece ser que estos versitos iban de las fábricas de caramelos de Buenos Aires, pues una de las coplitas decía:
10. Para la polémica entre Carrizo y Rojas, cfr. ABDUCA, Ricardo, "Trama y urdimbre en las tradiciones populares", 2010, y BENTIVEGNA (2013b). 
11. CARRIZO, Juan Alfonso. Cancionero popular de Salta, 1933, p. XXXIII.

12. Cfr. ROMANO, Eduardo. Intelectuales, escritores e industria cultural, 2012.

13. Cfr., al respecto, FERNÁNDEZ LATOUR DE BOTAS, Olga. Folklore y poesía argentina 1969 , p. 21 y ss.
Al alto cielo subí

En un globo, por más señas ;

Y lo que allá arriba vi

Fué uruguayas y porteñas.

Los fabricantes de estos caramelos y los cómicos de los circos ambulantes han contribuido mucho en la dispersión de cantares populares del Sur en las provincias del Norte del país. ${ }^{11}$

Lo seriado opera, pues, como zona exterior (es el mundo de la producción masiva de mercancías, en este caso de caramelos) pero también como condición de posibilidad - a través del dinero, de la producción serial de monedas - para la re-construcción del acervo.

La producción seriada de bienes, incluidos en este caso los bienes "discursivos", producen una realidad cultural que es rechazada de manera virulenta por Carrizo, en un discurso que encuentra su eco en las publicaciones de la época de diferente, y en algunos casos contrapuesta, orientación ideológica , ${ }^{12}$ desde la Iglesia Católica al Partido Comunista. En este aspecto, un punto importante es, para Carrizo, el deslinde de lo popular en relación con lo culto o con lo que puede entenderse como el producto de proyecciones cultas sobre lo popular -aquello que luego críticos como Augusto Raúl Cor$\operatorname{tazar}^{13}$ denominarán "proyección folklórica”. Ello conduce a Carrizo a encarar cuestiones que intentará sortear de manera satisfactoria, relegando las zonas del acervo recogido al que se le pueda asignar un autor letrado, urbano. Así, en el Cancionero de Salta Carrizo recoge fragmentos que recitan los paisanos pero que provienen de un archivo diferente, que califica como "culto" y que incluye composiciones de autores de diferentes procedencias, desde el romántico español Gustavo Adolfo Bécquer al catamarqueño Luis Franco, que había publicado en una fecha tan reciente como 1927 un pequeño volumen de poesía de su autoría titulado Coplas de pueblo, desde miembros de la generación romántica del 37 como Florencio Varela hasta el payador Gabino Ezeiza, cuyas composiciones pamperas circulan por toda la Argentina a comienzos del siglo XX.

El panorama en el que se mueve el trabajo de recolección de Carrizo se recorta sobre un fondo en el que la oralidad, aun cuando funcione para el recolector como una de las garantías más potentes del carácter legítimo de los materiales recogidos, aparece intrincada con diferentes formas de escritura, que no se limitan a hojas sueltas y cuadernos, sino que incluyen también, en diferente medida, otros materiales impresos, entre los que el recolector destaca la presencia de Biblias. Se trata, en definitiva, de un espacio que puede ser caracterizado a partir de la noción de oralidad mixta, acuñada por Paul Zumthor para refiere a la oralidad que se construye a partir de la escritura "dentro de un 
entorno en el que ésta tiende a debilitar los valores de la voz en el uso y en lo imaginario". ${ }^{14}$

Incluso en los documentos manuscritos - cuadernos, hojas sueltas, pliegos - que en muchos casos Carrizo toma como base documental para la elaboración de los cancioneros, el panorama de aquello que aparece registrado se muestra como un panorama complejo, que abarca desde cuadernos "de autor", que pueden pensarse incluso como esbozos de libros que podrían en teoría pasar a la imprenta, hasta pliegos que no conservan el nombre del poseedor, del compilador o el autor, como el que el recolector recibe en Salta de manos del historiador Bernardo Frías, quien, según reconstruye el propio Carrizo, lo había extraído a su vez de los papeles del gobernador Miguel Otero.

De esos cuadernos manuscritos, según se infiere en la introducción, Carrizo extrae una parte considerable de lo que va a presentar como el acervo poético legítimo de las provincias del noroeste, en especial las composiciones más extensas, como los romances o las décimas, que el pueblo habría "olvidado" en beneficio de las composiciones breves, que Carrizo clasifica como coplas, que habían sido trabajadas en el ámbito de la tradición española por Francisco Rodríguez Marín y que el joven Borges había también citado en su breve reflexión sobre las coplas populares de la ciudad de Buenos Aires que publica en 1926 en la revista Nosotros. ${ }^{15}$

Precisamente, el lugar de las composiciones más extensas, en especial del romance y de lo que Carrizo presenta como "glosa", será un tema de controversia en relación con otros modos de pensar - y de re-construir - lo que se considera el acervo legítimo. En efecto, desde un primer momento Carrizo reconoce que el romance, que era la "especie" de la poesía tradicional que había sido objeto de un trabajo de recolección y de clasificación más paciente en el caso de España de la mano, fundamentalmente, de Ramón Menéndez Pidal, no había sobrevivido, sino de un modo más bien marginal, en la Argentina y, presumiblemente, en toda la América hispana.

De este modo, Carrizo señala que la filiación hispánica en los cantos recogidos en Salta se reduce a 260 piezas, lo que representa un exiguo cinco por ciento del conjunto del total. Sin embargo, ello no lo lleva a postular una supuesta pertenencia no hispánica del cancionero de la provincia sino, por el contrario, a valorizar el trabajo de recolección del acervo popular en la Argentina frente al llevado adelante en España. En ese ámbito -el de la copla -, pese a la existencia de trabajos modélicos para Carrizo como los ya mencionados de Menéndez Pidal en el ámbito del romancero y de Francisco Rodríguez Marín en el de la copla, la recolección de materiales del acervo popular español se presenta como deficiente
14. ZUMTHOR, Paul. La letra y la voz, 1989, p. 21.

15. "Las coplas acriolladas", en Nosotros, nrs. 200-201, segunda época, Buenos Aires, 1926. Carrizo se refiere en varios escritos (entre ellos, en "La poesía popular y el Martín Fierro", de 1928) de manera positiva a la lectura que despliega Borges del Martín Fierro, en función, en ambos casos, de las lecturas monumentalizadoras del poema gauchesco planteadas por Ricardo Rojas y por Leopoldo Lugones. Carrizo rescata, asimismo, las observaciones de Borges acerca de la distancia entre el habla de los gauchos y la lengua literaria, en última instancia letrada, del poema de Hernández. 
16. CARRIZO, Juan Alfonso. Cancionero popular de Salta, 1933, p. XLIX.

17. NANCY, Jean-Luc. $A$ la escucha, 2007, p. 18.

18. CARRIZO, Juan Alfonso. Cancionero popular de Jujuy, 1935, p. C

19. BAUDRILLARD, Jean. EI sistema de los objetos, 1969, p. 114.

20. En la zona puneña que recorre Carrizo en su trabajo de recolección se habían producido varios conflictos por la posesión de la tierra, que tuvieron su ápice en 1874, en el combate de Quera entre los alzados de la puna y el ejército regular. A ello alude de manera detallada Carrizo en la nota 26 del Cancionero popular de Jujuy. A partir de este combate, el escritor jujeño Héctor Tizón urdirá la trama de su novela Fuego en Casabindo, publicada en 1969. En 1946, más de una década después de publicado el Cancionero jujeño de Carrizo, tuvo lugar una marcha a pie de pobladores puneños desde Jujuy hasta Buenos Aires, conocida como el "Malón de paz", para peticionar ante el presidente Juan D. Perón por la posesión de las tierras. El testimonio de uno de los participantes del Malón, el pintor puneño Hermógenes Cayo, puede verse en el documental homónimo de Jorge Prelorán (de 1967), sostenido por el Fondo Nacional de las Artes y por la Universidad Nacional de Tucumán, filme que contó con el asesoramiento de uno de los continuadores más importantes del trabajo folklorológico de Carrizo: Augusto Raúl Cortazar.

21. DELEUZE, Gilles y Félix GUATTAR1. Mil mesetas. Capitalismo y esquizofrenia, 2002, p. 323.
No hay pues suficiente material para cotejar y establecer la dependencia española que naturalmente deben tener por lo menos el veinte o treinta por ciento de nuestros cantos populares. La mejor prueba de ello es que hallé la filiación hispánica del cien por ciento de los romances y de las coplas, sólo el cinco. ${ }^{16}$

En $A$ la escucha, Jean-Luc Nancy afirma que "si entender es comprender el sentido (...) escuchar es estar tendido hacia un sentido posible y, en consecuencia, no inmediatamente accesible". ${ }^{17}$ Nos preguntamos qué es aquello que Carrizo está en condiciones de escuchar en el momento de recoger los cantares, es decir, cuáles son las condiciones de aparición y de registro de aquello que considerará como parte del legítimo acervo poético tradicional de las provincias del Noroeste argentino.

Leemos, por ejemplo, en la introducción al Cancionero popular de Jujuy un párrafo que condensa las tensiones en la construcción del acervo y el modo en que Carrizo intenta neutralizarlas:

Cuando llegaba a las casas, me recibían con glacial indiferencia, para ellos era preferible que siguiera el viaje pero yo bajaba de la mula, empezaba con dádivas y les decía que el gobierno estaba interesado en entregarles las tierras, entonces entraba en conversación, ocupaba la cocina en donde se reúne la familia y entre charla y charla copiaba los cantares populares; por cada copla que me dictaban les pagaba diez centavos, vi que con ello los estimulaba y generalicé el procedimiento. Más cantares he recogido en Jujuy, así en la paz del hogar, que en las fiestas, porque en éstas los paisanos se alcoholizaban fácilmente y no cantaban bien sus coplas, pues principiaban con los versos de un cantar y terminaban con los de otro. ${ }^{18}$

El objeto que integra una colección, en este caso la colección de los cantos populares, es el objeto abstraído, purificado y desterritorializado de su uso, ${ }^{19}$ desligado de un territorio que es también un objeto de disputa en cuanto a su posesión histórica, ${ }^{20}$ algo que Carrizo, en este fragmento, no puede soslayar.

Para Carrizo, el acervo de la poesía popular vendría a confirmar la pertenencia al tronco común hispánico de aquello que constituye el fundamento de la cultura argentina, que sólo puede definirse como nacional en un sentido muy acotado: es nacional en la medida en que está presente en el territorio argentino, pero no en el sentido en que constituye un objeto peculiar de ese territorio. Si, como afirman Deleuze y Guattari en mil mesetas, el ritornello - que incluye, entre sus variantes posibles, al ritornello folklórico, copla, glosa o romance - crea el territorio a través de su expresividad rítmica, ${ }^{21}$ la operación de Carrizo separa de manera tajante texto verbal, 
música y territorialidad. Los rasgos diferenciales - y en última instancia irrecuperables, conflictivos - del canto popular son, en este punto, relativizados por Carrizo con argumentos que se asientan en criterios lingüísticos y filológicos.

\section{Lenguas y conflicto}

Un problema glotopolítico recurrente es, para Carrizo, la presencia en el acervo hispanizante de composiciones en lenguas indígenas, en especial en quichua - extendida en algunas zonas del noroeste, aunque sobre todo en la provincia de Santiago del Estero, que Carrizo deja explícitamente fuera de su ámbito de trabajo y cuya tradición poética será recogida, con su aval, por Orestes Di Lullo. Estos materiales en quichua, que ya habían sido objeto de atención por parte de aquellos que iniciaron con sus trabajos la investigación arqueológica y etnográfica en la Argentina, en especial por parte de Adán Quiroga, Samuel Lafone y Quevedo y Juan B. Ambrosetti, así como por el francés Éric Boman, representa para Carrizo un sector marginal, en cuanto a la cantidad de producciones recogidas. Asimismo, ese componente cuantitativamente marginal de los cancioneros populares será objeto de Carrizo en una reflexión que tiende a evidenciar su condición de material derivado del tronco común hispánico, a partir básicamente de dos argumentos: su condición de materiales traducidos -pasibles de ser inscriptos en la tradición europea, a veces más allá de lo estrictamente castellano - y la presencia de componentes formales que revelan la preeminencia de lo hispánico, en especial la rima. ${ }^{22}$

El problema del choque de lenguas vuelve a plantearse en las palabras introductorias que Carrizo escribe para el Cancionero popular de Santiago del Estero publicado en 1940 por Orestes Di Lullo. Es un volumen editado también por la Universidad de Tucumán, y se adecua sin demasiadas tensiones a los patrones que rigen la serie de grandes cancioneros de Carrizo. Sin embargo, Santiago representa un caso que no se subsume sin más en la serie de Cancioneros de Carrizo. En efecto, hay dos cuestiones que resultan anómalas en relación con el paradigma interpretativo desplegado por Carrizo y que Di Lullo parece no del todo dispuesto a minimizar: la existencia de una tradición poética en lengua quichua que, por la cantidad de hablantes y por la riqueza de los textos recogidos, no puede inscribirse en la idea de mero residuo condenado a desaparecer, como había planteado Carrizo en relación con los cantares en lengua aborigen de las provincias andinas, y la existencia de
22. Cfr., al respecto,

BENTIVEGNA, 2013. "El canto y la letra: disputas en torno a lo tradicional en Juan A. Carrizo y Ricardo Rojas", ed. cit. 
23. DI LULLO, Orestes.

Cancionero popular de Santiago

del Estero, 1940, p. X - XI.

24. CARRIZO, Juan Alfonso.

Prólogo a. O. Di Lullo,

Cancionero popular de Santiago

del Estero, 1940, p. VII. una forma poética altamente productiva por su vitalidad, que no se sujeta a los cánones prosódicos de las especies poéticas recogidas en esas mismas provincias: la vidalita. Ambas, coplas quichuas y vidalas, afirma Di Lullo:

....aportan a la literatura popular argentina una atrayente novedad de alto valor estético y lingüístico. Las vidalas porque confirman la impresión de que el pueblo es capaz de hacer poesía, y el cancionero quichua porque significa una positiva contribución de las lenguas que se hablaban y aún se hablan en la provincia. ${ }^{23}$

Con todo, Carrizo, a través del prólogo y de las notas del volumen Di Lullo, plantea una lectura crítica que acomoda los materiales a sus hipótesis hispanistas de partida:

Fiel a su concepción científica del folklore, Di Lullo entiende que los cantares tradicionales de una región americana no pueden ser considerados aisladamente de los de igual índole de la Madre Patria, no pueden ser tenidos como autóctonos en el mismo grado en que se consideran franceses los recogidos en Francia e Ingleses los hallados en Inglaterra. Aunque en todas partes donde se estudie la poesía del pueblo se imponga la necesidad de realizar la búsqueda de los antecedentes histórico-literarios que revelen su origen, en América esa necesidad cobra trascendental importancia, debido a que llevamos cuatro siglos de influencia hispánica, y no es dable presumir que un cantar tradicional puede estar exento de esa influencia. Cuando el doctor Di Lullo se entregaba a esa tarea, razones ajenas a su buen deseo lo obligaron a confiarla a nuestras manos. ${ }^{24}$

Si reinscribimos las palabras de Carrizo en el campo discursivo de los estudios sobre la cultura popular de los años 30 y 40, resulta evidente la dimensión polémica que encierra, en relación no sólo con el discurso culturalista de matriz euríndica - que propugnaba la fundición de lo indígena y lo hispánico - elaborado desde los años 20 por Ricardo Rojas sino también con el de intelectuales de la misma generación de los alumnos de Carrizo que estaban publicando por entonces su primeras intervenciones.

Es el caso, por ejemplo, de Bernardo Canal Feijóo, quien en 1937 da a conocer su Ensayo sobre la expresión popular artística en Santiago, su provincia natal, al que seguirá en 1938 el volumen Mitos perdidos. Allí - a partir de un complejo plafón teórico que abreva en la antropología de La rama dorada de James Frazer y en el psicoanálisis social del Freud de Tótem y Tabú -, Canal aborda el problema de lo popular en función de las problemáticas que se presentan en su propia provincia, Santiago del Estero, ubicada en una zona intermedia entre las 
provincias históricas del Tucumán, las provincias de la zona del litoral y las del centro de la República.

Para Canal Feijóo, que había publicado por entonces tres volúmenes de poesía y que dirigía en Santiago la revista $L a$ Brasa - en diálogo cotidiano con el grupo porteño de Sur y, a través de él, con algunas de las grandes figuras de la literatura europea (Roger Caillois, Giuseppe Ungaretti, etc.) - el rasgo que permite pensar centralmente el problema de la cultura popular santiagueña no tiene que ver tanto con la pertenencia a una región determinada, sino con una característica más huidiza y, en consecuencia, problemática: la paradoja de una provincia "mediterránea", en un sentido etimológico que para Canal es determinante para definir la posición cultural y política marginal de la región como una posición cuasi insular. ${ }^{25}$

\section{Un paisaje desconfigurado}

Una cuestión fundante para Canal Feijóo es la de pensar las relaciones entre aquello que se designa como "folklore" y el espacio en que este funciona, es decir, pensar el paisaje como categoría, en términos de una relectura del idealismo nacional similar al que en esos mismos años estaba planteando Heidegger en relación con la Heimat de la Alemania meridional y que será introducido en la Argentina a principios de los años 40 por el filósofo Carlos Astrada, que había seguido los cursos del filósofo alemán en Friburgo y que pensará, en clave americana, la idea heideggeriana de "paisaje creador".

Para Canal, el paisaje de Santiago, que no puede asimilarse ni al paisaje llano de la pampa ni, mucho menos, a las estribaciones andinas de las provincias del noroeste, así como tampoco al serrano de las provincias centrales como Córdoba o San Luis, es un paisaje que convoca la intervención de aquel que lo mira. No es objeto de contemplación, sino de experiencia:

No voy a distraerme aquí en una descripción literaria del paisaje santiagueño. Para muchos sé que no existe como paisaje, pues no es ni pampa ni montaña. Es bosque, broza, maleza, salina. Mientras los otros paisajes están diseñados en distancia, en fuga, en infinitud, en masa, éste sólo se dibuja en rincones, en ocultos detalles casuales. No es para ser visto desde el tren, o desde el aeroplano. En cierto modo, pide la convivencia del sujeto humano: no es un simple éxtasis. El hombre está ante la pampa, ante la montaña, desde el punto de vista del sentimiento del paisaje; desde el mismo punto de vista nunca podría estar "ante" el bosque: precisa estar en él, envuelto, inmerso en él. ${ }^{26}$
25. En efecto, el territorio histórico de la provincia de Santiago del Estero, antes de la ampliación producida por la conquista definitiva de las zonas en manos de los aborígenes del Chaco por parte del Estado nacional, estaba delimitada por el curso de dos grandes ríos, el Salado y el Dulce.

26. CANAL FEIJÓO, Bernardo. Ensayo sobre la expresión popular artística en Santiago, 1937, p. 9-10. 
27. CANAL FEIJÓO, Bernardo, Burla, credo, culpa en la creación anónima argentina [1951], 2010, p. 89.

28. CARRIZO, Juan Alfonso.

"Nuestra poesía popular. Apuntes para su estudio”, 1927, p. 248.
Se trata de un paisaje sometido a un proceso de transformación que se articula con los procesos descriptos por Carrizo en el prólogo de sus cancioneros, donde se constata la paradoja de que una de las zonas donde se recogen la mayor cantidad de cantares (la provincia de Tucumán) coincide con la de mayor desarrollo industrial.

El escrito de 1937 se encuentra en el eje de un conjunto de intervenciones sobre lo popular (la artesanía, el tejido, las leyendas, lo teatral) que culminarán en el más importante de los ensayos sobre cuestiones relacionadas con la cultura popular publicados por Canal Feijóo, Burla, credo y culpa en la creación anónima, aparecido en el año 1951. En "Sociología, etnología y psicología del folklore”, el prólogo del volumen, Canal señala los puntos que separan su proyecto del de los folklorólogos nucleados en torno a la figura de Carrizo, quien por entonces había logrado ocupar un lugar importante de consagración institucional a partir de la fundación del Instituto Nacional de la Tradición y de la participación en las instituciones académicas y científicas argentinas relacionadas con la investigación folklórica. "El folklore -afirma polémicamente Canal - tiende a ser visto como algo que alguien - uno o muchos - hicieron una vez, hace años, y que las generaciones sucesivas deben seguir repitiendo con filial y devoto automatismo". ${ }^{27}$

En la recolección de Canal, desparecen las especies que planteaban una relación más directa con la tradición letrada de matriz hispánica, como los romances, que habían sido objeto de interés por parte de Ricardo Rojas y de su grupo -lo que confluirá en la publicación en 1941 por la Universidad de Buenos Aires de los dos volúmenes del Romancero de Ismael Moya-, y de la glosa, que era la "especie" (en el sentido en que los folklorólogos usan este concepto, extraído del discurso de las ciencias naturales) que Carrizo trabajaba por entonces de manera sistemática y cuya génesis en la literatura española y su transmisión a América estudiará en forma detallada en los Antecedentes hispano-medioevales.

Son elocuentes en este sentido las palabras de Carrizo en un artículo temprano, cuando sólo se había dado a conocer el primer volumen de la serie de cancioneros, "Nuestra poesía popular”, publicado en la revista Humanidades de la Universidad de La Plata: "Dividiremos el estudio de los cantos populares en tres secciones, a saber: romances, canciones y coplas, porque en estas tres agrupaciones se resumen todas las manifestaciones estéticas del pueblo, exactamente como en la división aristotélica se clasificaba toda la flora terrestre en tres grupos: árboles, arbustos y hierba" ${ }^{28}$ Precisamente, para Canal la tradición folklórica se plasma centralmente en las coplas, la especie que para Carrizo se piensa como hierba -que, como recuerda en 
varias ocasiones Deleuze, puede pensarse como red horizontal que no admite jerarquías o como rizoma- y no como rama de un árbol enraizado en la tradición hispánica.

A su vez, las coplas son objeto de clasificación por parte del autor santiagueño., con las implicancias que ello tiene desde un punto de vista teórico. Las clasificaciones que propone Canal como principio de organización del material recopilado en campo tienen en cuenta tanto el contenido de las coplas como cuestiones puramente formales. En este punto, en la articulación de Canal aparece la especie vidala, como una forma irreductible a los moldes hispánicos y, en este sentido, poco jerarquizada por Carrizo:

En la múltiple estructura de la vidala damos con las más variadas combinaciones métricas. La diversidad de la estructura literaria corresponde a la enorme variedad del género musical que se designa con ese nombre, que no es exclusivo de Santiago -como no lo es ninguno de los otros-, pero que tiene formas exclusivamente santiagueñas. Lo intaxativo del género llega a permitir a veces la completa desfiguración de la estrofa, sustentándose principalmente la expresión literaria, del estribillo, que constituye el elemento riguroso de ésta. ${ }^{29}$

La vidala como canto de nostalgia por la tierra, de "vaga angustia metafísica", no implica una mera transmisión de una forma tradicional, sino una forma en que la tradición -entendida como un hecho autónomo en última instancia del paisaje, una forma no territorial codificada en los cánones poéticos provistos por la crítica hispanista- se articula., como voz y como canto, en el paisaje. Es una forma mutable, que se desconfigura y muestra, en ese movimiento, su condición de canto ligado con los ciclos agrarios y, en consecuencia, con la tierra. Lo folklórico, en general, se produce cuando el fenómeno práctico "corresponde a un punto de estabilidad y permanencia orgánica de la relación local del hombre con la tierra". ${ }^{30}$

$\mathrm{Al}$ respecto, son especialmente claras las palabras citadas al respecto por Canal en su Ensayo, palabras que pone en boca de un anónimo cantor popular:

\footnotetext{
"Cosa rara, las vidalas brotan de los sentimientos del paisano en el mismo tiempo que el Coyuyo, el Cacuy, el Crespín, y algunas otras aves. Pasado el Carnaval ya no hay vidalas, solo hay bailes cansados ya por la tarea cumplida. Vuelve el paisano en busca de orientaciones para cumplir con su deber, aunque sea como sucede, de trabajar de sol a sol con la pala o el hacha por 1,20 al día. Pero él tiene su tiempo en el cual se escapa de sus patrones por más que necesiten de él: es desde el mes de diciembre, porque se prepara en sus dichos, en sus vidalas y renace su espíritu porque parece que se desahoga o descansa, su alma, y hasta
}

29. CANAL FEIJÓO, Bernardo.

Ensayo sobre la expresión popular artística en Santiago, 1937, p. 99-100.

30. Ididem,p. 102. 
31. CANAL FEIJÓO, Bernardo.

Ensayo sobre la expresión popular artística en Santiago, 1937, p. 107; las comillas son del autor.

32. Ibidem, p. 18.

33. Ibidem, p. 18.

34. DELEUZE, Gilles y Félix GUATTAR1. Mil mesetas. Capitalismo y esquizofrenia, 2003, p. 344. En relación con la cuestión de los pueblos que surgen "de las entrañas de la tierra,", hay que recordar que Canal Feijóo tradujo al castellano La civilización chaco-santiagueña y sus correlaciones con la del Viejo y Nuevo Mundo, el monumental estudio de los hermanos Duncan y Emilio Wagner publicado en 1934. Estos arqueólogos franceses radicados en la provincia de Santiago del Estero hipotetizaron, a partir de sus investigaciones de campo en el noreste de la provincia, la existencia de una civilización sumergida, anterior al establecimiento del imperio incaico, una civilización sumergida en la región chaqueña a la que denominaron "cultura chaco-santiagueña" (cfr. al respecto B. OCAMPO, 2004, p. $67 \mathrm{y}$ ss.). Aun cuando Canal no comparte en su totalidad las hipótesis de los hermanos Wagner, se encuentran huellas de las investigaciones arqueológicas de los franceses en varios de sus ensayos, en especial en el dedicado en 1976 a Leopoldo Lugones: Lugones y el destino trágico.

35. CANAL FEIJÓO, Bernardo.

Ensayo sobre la expresión popular artística en Santiago, 1937, p. 88. a veces parece que pelea cuando baila una chacarera, del gusto y contento que pone en el acto". ${ }^{31}$

Para Canal Feijóo, es necesario volver a pensar el sujeto y el producto de aquello que se considera folklore, que piensa, en un gesto que es sustancial para entender la distancia con el proyecto de los folklorólogos, no en términos de origen y de evolución, que para el intelectual santiagueño señala (aun sin nombrarlo) los límites de la aproximación de Carrizo, sino de uso y de apropiación. En este sentido, el comienzo del Ensayo de 1937 es sintomático, en la medida en que polemiza, ya en su primer párrafo, con lo que designa como "los folklorólogos argentinos”, cuyo afán es “establecer procedencias a las especies folklóricas del país, como si tratándose de la materia no pudiese haber otro valor que la originalidad". ${ }^{32}$

A su vez, el sujeto del folklore es, para Canal, el pueblo en la medida en que "toma sus especies donde las encuentra; lo que importa es la presuposición que tal hecho encierra, de determinada condiciones psicológicas y sociales que permiten el hallazgo, el encuentro selectivo y la conservación de la especie". ${ }^{33}$

Canal enfatiza su propia pertenencia al pueblo, aun cuando las formas en las que ese pueblo se enraiza en el territorio esté marcado por la falta, como el pueblo de los románticos europeos al que se refieren Deleuze y Guattari como pueblo "que está mediatizado por la tierra, surge de sus entrañas y está dispuesto a volver a ellas"34: la autoctonía no es lo que ese pueblo manifiesta, sino algo que para Canal debe ser deslindado en el proceso mismo de creación folklórica, en un gesto que lo distancia marcadamente de la noción de pueblo como una entidad estática y cerrada en sí misma, más reproductiva que creadora, desplegada por Carrizo. "En nuestra condición de pueblo - leemos en el Ensayo de Canal Feijóo - nos hallamos en un momento singular, con una historia colonial a las espaldas y un presente inmigratorio”, lo que implica pensar el modo en que se va produciendo "la síntesis de nuestra autenticidad": "El folklore es una manifestación de la realidad histórico-social que el pueblo vive, realidad que puede o no ser favorable a la expresión estética”. ${ }^{35}$

\section{Oralidad, canto, silencio}

De manera programática, en las primeras páginas de Burla, credo, culpa..., Canal plantea una relectura del acervo poético popular desde una clave de interpretación que no puede 
dejar de leerse sino en función polémica con respecto a las posiciones sustentadas por Carrizo y sus discípulos, a quienes, con todo, en ningún momento alude de manera directa. En principio, se trata para Canal, en este caso, de trabajar sobre dos "especies" folklóricas que, a su juicio, no habían merecido aun la suficiente atención: las leyendas y el drama, es decir, la expresión narrativa y la expresión teatral, que se presentan como formas menos jerarquizadas por parte de las investigaciones folklóricas que las expresiones en verso, que Canal subsume bajo el concepto general de "expresión poética".

En efecto, Canal Feijóo entiende la impactante cantidad de recolecciones de la poesía popular de las provincias del noroeste como una operación relacionada con una concepción alta, y en última instancia no popular, de la cultura que entiende lo poético en términos de una forma más o menos rígida que responde a patrones ritmos -en general, se trata de octosílabos de rima consonante- regular. Ello se relaciona, para Canal, con la difusión de una cultura letrada, alta, que se imponen a partir del prestigio de la misma forma.

Canal retoma en su ensayo la dicotomía de forma y fondo, que en Carrizo, como habíamos visto, resulta un aspecto sustancial para afirmar la pertenencia estrictamente hispánica del acervo en lenguas indígenas recogido en las provincias del noroeste. El problema de la lengua, al mismo tiempo, se replantea desde el mirador que es para Canal la provincia de Santiago, donde la presencia de la lengua quichua es mucho más marcada que en cualquier otro punto de la Argentina.

La oralidad que define la transmisión del acervo tradicional no funciona como una instancia en sí misma conservadora, sino que es el principio que explica la variabilidad de los productos poéticos del folklore:

Impide la cristalización de la forma; y así encontramos la infinita variación, condicionada al gusto o a la capacidad del sujeto. La variación suele, en general, ir unida a cierta tendencia a la corrupción formal que parece inherente al destino de la expresión popular, y éste es el mayor inconveniente que la oralidad presenta, pues si la oralidad significa la articulación viviente de la forma, la variabilidad contiene su principio de muerte..$^{36}$

El problema de la lengua se confunde, con un dejo que puede remitir a la Estética de Benedetto Croce - muy presente en el pensamiento argentino de la primera mitad del siglo XX -, con el problema mismo de la expresión:

La expresión oral tiene, como problema, un punto de partida absoluto: el idioma. Supone una lengua. En Santiago, supone dos: el español y el quichua. Supone una u
36. Ibidem, p. 80 . 
37. Ibidem, p. 81.

38. Ibidem, p. 83.

39. Ibidem, p.102. otra, naturalmente; a veces supone también una y otra; mas lo interesante de la expresión bilingüe comienza en el punto en que ambas lenguas se muestran en pugna, procuran recíprocamente excluirse. Para que esta situación se produzca realmente es necesario que, como en ese caso de la coexistencia del español y el quichua, se trate de lenguas de estructura distinta, correspondientes, desde luego, a pueblos de raza e historias diferentes. Que haya una recíproca incapacidad de penetrar y ser penetrado en uno y otro. ${ }^{37}$

La expresión representa, para Canal, una totalidad en sí misma, que conecta al pueblo, más que con un origen, con su fondo esencial, aun cuando este aparezca, en muchos casos, al menos en la superficie, negado:

$\mathrm{Al}$ acercarme a la expresión popular he llegado a ver que el pueblo nunca habla en vano, y que no tiene más modo de expresarse que por y desde sus raíces. Porque al expresarse se afirma en lo que tiene de valores esenciales, y éstos coinciden para él en sus fondos (insobornables) de raza y de patria, es decir, de historia antropológica y social”. ${ }^{3}$

En la expresión folklórica santiagueña la existencia de las dos lenguas se presenta como un hecho absolutamente definitoria del hecho popular. En este sentido, no se trata para Canal de pensar lo folklórico en términos de una homogeneidad formal y lingüística que remitiría, en última instancia, a una homogeneidad racial, sino de enfatizar el carácter complejo, heterogéneo y no fundido de los productos populares. El choque étnico, el que se produce entre españoles e indios al comienzo de la conquista y durante la colonia o el que tiene lugar entre paisanos e inmigrantes a partir del siglo XIX, no se refleja de manera directa en los productos tradicionales. Por el contrario, "a cada uno de estos momentos máximos parece corresponder un íntimo silencio creacional colectivo" ${ }^{39} \mathrm{La}$ no correspondencia entre el lenguaje heredado y las nuevas realidades producen, para Canal, que el "alma colectiva" se calle inexorablemente. Luego de la sedimentación del choque, aflora, de manera inesperada, el "acento", conectado con un fondo étnico y psíquico que, lejos de "enriquecer" el producto folklórico, lo vuelve más pobre y precario.

Si la estrategia de Carrizo en relación con los textos en lengua quichua es evidenciar, a través de la movilización de las diferentes zonas del archivo, aquello que los muestran como subproductos de la cultura hispánica, es decir, la puesta en evidencia del carácter secundario, derivado y en última instancia la condición de apéndice en relación con una tradición alta, la de Canal consiste en desentramar la presencia de una voz acallada, oculta, que se manifiesta en una superficie que pareciera en principio monolingüe. 
En el caso de las tradiciones populares santiagueñas, la heteroglosia aparece como constitutiva. Ello se puede resumir en tres puntos fundamentales, puntos que no plantean una coexistencia de las lenguas, sino que se refieren más bien sus conflictos a partir de las formas de uso y de apropiación que la forma minorizada, en este caso el quechua, lleva adelante en relación a la lengua de cultura:

Que hay especies presentadas exclusivamente en español. $\mathrm{Y}$ otras exclusivamente en quichua.

Que cuando la misma especie es transferida de un idioma a otro va acompañada de un cambio de intención o sentido esencial.

Que cuando los dos idiomas se entretejen o combinan dentro de una misma especie, el quichua no tiene, en general, otro objeto que el de señalar una intención de contraste o de contradicción con el español. ${ }^{40}$

Canal puede coincidir con los "folklorólogos" de la línea de Carrizo en las causas que, desde su perspectiva, determinan el empobrecimiento generalizado de la expresión popular, que define en términos de una "pérdida del lenguaje". La destrucción del paisaje se articula, así, con la desconfiguración del lenguaje: el des-paisajamiento produce un empobrecimiento de la palabra.

Para Canal son centralmente tres los puntos que permiten explicar el proceso: la persistencia de la visión sarmientina, que identifica la expresión popular folklórica con la "barbarie"; la inmigración (Canal hablará del "silencio mismo del inmigrante, por desambientación o despaisamiento") y el "cambio de las condiciones materiales de existencia”, que desconfigura el paisaje -en Santiago, concretamente, se arrasa el bosque originario- y se produce el éxodo en masa de la población ("Cierto espíritu de desarraigo y de nomadismo en el pueblo de la campaña”) hacia otros centros urbanos, como Tucumán, sede de la industria azucarera. A ello Canal agrega otro factor: el de la inmigración europea. En este aspecto, Canal, aun siendo hijo de españoles llegados a la Argentina a fines del siglo XIX, comparte la alarma con respecto a los procesos de mutación cultural que encarnan los inmigrantes europeos. Así, el ensayista santiagueño se refiere de modo despectivo a la "inmigración inculta, mal administrada y regida, mal contrarrestada espiritualmente que no suplanta los valores arcaicos por otros mejores, sino que los anula" ${ }^{41}$

Asimismo, Canal coincide con el grupo de los folkloristas en cuanto a una distinción básica, que está en la base de la oscilación entre el uso de las expresiones "poesía popular” y "poesía tradicional”. En todo caso, para Canal, como para Carrizo o Jacovella, es menester distinguir entre la poesía ge-
40. Ibidem, p.83.

41. Ibidem, p. 24. 
42. ZUMTHOR, 1989, La letra y la voz, 1989, p. 156.

43. RICOEUR, Paul. La memoria, la historia, el olvido, 2004, p. 216. nuinamente popular y sus imitaciones, la poesía "pseudo-popular" que trabajan con un "símil" lenguaje del pueblo, que se diferencia de la "impostación de la voz" que distingue a la poesía genuina. Se habla, así, de cierto "endomingamiento verbal" de la poesía popular santiagueña, un rasgo que para Canal es definitorio para distinguirla, en una lógica que veíamos presente también en Carrizo, de formas no legítimas de lo popular, relacionadas sobre todo con proyecciones sobre lo folklórico desarrolladas desde los centros urbanos.

Sin embargo, hay una distancia muy marcada entre la concepción de poesía tradicional desarragiada de un territorio concreto, tal como la plantea Carrizo, y el modo en que Canal piensa la relación con la tierra, sometida a un proceso de destrucción y de desolación. En la concepción de Canal Feijóo hay un trabajo sobre la palabra que caracteriza a la producción poética popular santiagueña y que entra en serie con el resto de las producciones folklóricas que Canal aborda en su Ensayo, como el trenzado o el tejido. Como dirá muchos años después Paul Zumthor, "del mismo modo que el arma, el jarrón, el vestido, resultan del trabajo manual, sin mediación maquinista, el discurso es producido por el trabajo fisiológico de la voz" ${ }^{42}$ Tanto para el ensayista santiagueño como para el filólogo suizo, obsesionados ambos por los rostros que asume la tradición oral, la voz colectiva existe, en definitiva, en un plano que se inscribe en el de la producción artesanal, con su carácter anónimo, su condición frágil, su irreductiblidad.

\section{Conclusiones: escuchar y archivar}

Paul Ricoeur afirma que el momento del archivo es inseparable del momento de la escritura. En el archivo el testimonio puede ser "recogido por escrito, presentado, depositado", ${ }^{43}$ Desde el punto de vista de la configuración de lo historiográfico, el momento del archivo es el de la construcción del acervo como un conjunto depositado. La deposición de los restos es la condición de posibilidad de las instituciones específicas dedicadas a la recopilación del acervo que, en ese mismo acto recopilatorio, lo constituyen. En el archivo -el lugar físico en el que la voz del otro, del testigo, se aloja y se resguarda - el testimonio, casi siempre oral, es resguardado en un lugar investido del poder de conservación -el cancionero, pues, como arcón- y, al mismo tiempo, se torna disponible para su uso y para su reiteración.

El archivo es, para Carrizo, el lugar en el que se produce la puesta en escritura y la normalización de un objeto discursi- 
vo, la literatura popular o tradicional legítima, que se presenta como una proyección de un archivo mayor que no puede ser repuesto del todo y que el propio Carrizo piensa como un archivo en proceso de construcción: el archivo de la poesía tradicional hispánica. Desde allí, las tradiciones del mundo oral de las provincias del Norte que -como subraya Eric Havelock $^{44}$ para todo el universo de lo oral, plantea un entramado entre poesía, música, y danza- es sometido a un proceso de depuración de una supuesta palabra pura que viene a coincidir con la letra castellana. En pocas palabras, a partir de un hispánico archivo hipotético que el propio Carrizo ayuda a conformar con contribuciones macizas como los Antecedentes hispano-medioevales, el catamarqueño puede depurar la voz de la tradición, desarraigar esa voz de un territorio e inscribirla, soslayando en general las tensiones que ello plantea, en la serie de la gran poesía en lengua española, cuyas raíces se encuentran en la Edad Media y que se despliega en España y en América durante el Siglo de Oro.

Para Canal Feijóo, en cambio, el archivo de lo popular es la puesta en escritura de una voz que debe pensarse en relación con un territorio. De una voz que, como el paisaje mismo en que nace, se encuentra sometida a un proceso de desconfiguración, de empobrecimiento y de silenciamiento. La escucha de esa voz es, en este caso, diferente. No se trata de oír en el canto un retorno al pasado, sino de localizar las "potencias más secretas del decir”, una serie de problemas generalmente omitidos, o demasiado secundarizados, en la consideración del fenómeno folklórico argentino, que de ese modo ve escamoteada gran parte de su sustancia y envergadura" ${ }^{45}$

Si la excentricidad, como afirma Raúl Antelo, ${ }^{46}$ se configura como el lugar desde donde se lee y se construye la comunidad imaginaria que es la nación, las aproximaciones a la poesía tradicional pensarán su condición comunitaria sobre la base de un desplazamiento temporal (se trata de reconocer, señalar y preservar las reliquias de una tradición que todavía sobreviven) y, al mismo tiempo, espacial. Se trata, en este punto, de escuchar la voz del pueblo en aquellos zonas que permanecen, en el imaginario de los folklorólogos, como no tocadas por el proceso de modernización o, por el contrario, sometidas a un proceso de modernización que ha terminado por destruir la idea misma de paisaje en el que la tradición poética estaba arraigada. Es allí, entre la búsqueda de una supuesta pureza y la realidad apabullante del desarraigo donde se pone en juego la noción misma de poesía popular en la Argentina de la primera mitad del siglo XX.
44. HAVELOCK, Eric. La musa aprende a escribir. Reflexiones sobre oralidad y escritura desde la antigüedad hasta el presente, 1996, p. 112.

45. CANAL FEIJÓO, Bernardo, Burla, credo, culpa en la creación anónima argentina [1951], 2010, p. 88.

46. ANTELO, Raúl. Algaravia.

Discursos de nação..2010, p. 12. 


\section{Referencias}

ABDUCA, Ricardo, "Trama y urdimbre en las tradiciones populares”, estudio preliminar a B. Canal Feijóo, Burla, credo, culpa en la creación anónima argentina. Buenos Aires: Biblioteta Nacional-Subsecretaria de Cultura de Santiago del Estero, 2010.

ANDERSON, Benedict. Comunidades imaginadas. Reflexiones sobre el origen y la difusión del nacionalismo. Trad: E. Suárez. México: Fondo de Cultura Económica, 1993.

ANTELO, Raúl. Algaravia. Discursos de nação. Florianópolis: UFSC, 2010.

BAUDRILLARD, Jean. El sistema de los objetos. Trad. Francisco González Aramburu. México: Fondo de Cultura Económica, 1969.

BENTIVEGNA, Diego. El poder de la letra. Literatura y domesticación en la Argentina. La Plata: UNIPE, 2011. ., "El canto y la letra: disputas en torno a lo tradicional en Juan A. Carrizo y Ricardo Rojas", en E. N. de Arnoux y S. Nothstein (comps.). Temas de glotopolítica. Buenos Aires: Biblos, 2013. En prensa.

CANAL FEIJÓO, Bernardo. Ensayo sobre la expresión popular artística en Santiago. Buenos Aires: Compañía Impresora Argentina, 1937.

. Mitos perdidos. Buenos Aires: Compañía Impresora Argentina, 1938.

La expresión popular dramática. Tucumán: Universidad Nacional de Tucumán, 1943.

. Burla, credo, culpa en la creación anónima argentina [1951]. Buenos Aires: Biblioteca Nacional-Subsecretaria de Cultura de Santiago del Estero, 2010

CARRIZO, Juan Alfonso. "Nuestra poesía popular. Apuntes para su estudio", en Humanidades, t.15., La Plata, 1927.

“La poesía popular y el Martín Fierro", en Nosotros, a. 22, nr. 224, Buenos Aires, 1928.

Cancionero popular de Salta. Buenos Aires:

Universidad Nacional de Tucumán - A. Baiocco, 1933. 
. Cancionero popular de Jujuy. Buenos Aires:

Universidad Nacional de Tucumán - A. Baiocco, 1935.

Cancionero popular de Tucumán. Buenos Aires:

Universidad Nacional de Tucumán - A. Baiocco, 1937.

. Prólogo a. O. Di Lullo, Cancionero popular de

Santiago del Estero, Buenos Aires: Universidad Nacional de Tucumán, 1940.

CASANOVA, Pascale. La república mundial de las letras. Trad: Jaime Zulaika. Barcelona: Anagrama, 2001.

CHAMOSA, Oscar. Breve historia del folklore argentino (1920-1970). Buenos Aires: Edhasa, 2012.

CHEIN, Diego. "Provincianos y porteños. La trayectoria de Juan Alfonso Carrizo en el período de emergencia y consolidación del campo nacional de la folklorología (19351955)”, en F. Orquera (comp.). Ese ardiente jardín de la República. Formación y desarticulación de un "campo" cultural. Tucumán, 1870-1975. Córdoba: Alción, 2010.

CORVALÁN, Octavio. Bernardo Canal Feijóo o la pasión mediterránea. Santiago del Estero: Universidad Nacional de Santiago del Estero, 1988.

DE CERTEAU, Michel. La escritura de la historia. Trad: Jorge López Moctezuma. México: Universidad Iberoamericana, 1988.

DELEUZE, Gilles y Félix GUATTAR1. Mil mesetas. Capitalismo y esquizofrenia. Trad. José Vázquez Pérez. Valencia: Pre-textos, 2002.

DERRIDA, Jacques . Mal de archivo. Una impresión freudiana. Trad. Paco Vidarte. Madrid, Trotta, 2004.

DI LULLO Orestes. Cancionero popular de Santiago del Estero. Tucumán: Universidad Nacional de Tucumán, 1940.

JACOVELlA, Bruno. Juan Alfonso Carrizo. Buenos Aires: Ediciones Culturales Argentinas, 1963.

FERNÁNDEZ LATOUR DE BOTAS, Olga. Folklore y poesía argentina. Buenos Aires: Guadalupe, 1969.

HAVELOCK, Eric. La musa aprende a escribir. Reflexiones sobre oralidad y escritura desde la antigüedad hasta el presente. Trad. Antonio Alegre Gorri. Barcelona: Paidós, 1996.

MAINGUENEAU, Dominique (2009). Discurso literário.

Trad. Adail Sobral. São Paulo: Contexto, 2009. 
NANCY, Jean-Luc. La escucha. Trad. Horacio Pons. Buenos Aires: Amorrortu, 2007.

OCAMPO, Beatriz. La nación interior. Canal Feijóo, Di Lullo y los Hermanos Wagner. El discurso culturalista de estos intelectuales en la provincia de Santiago del Estero. Buenos Aires: Antropofagia, 2005.

RICOEUR, Paul. La memoria, la historia, el olvido. Trad. Agustín Neira. Buenos Aires, Fondo de Cultura Ecónomica, 2004.

ROMANO, Eduardo. Sobre poesía popular argentina. Buenos Aires: Centro Editor de América Latina, 1983. Intelectuales, escritores e industria cultural. Buenos Aires: La Crujía, 2012.

SARLO, Beatriz. Una modernidad periférica. Buenos Aires, 1920-1930. Buenos Aires: Nueva Visión, 2003.

TERÁN, Oscar.. "El dispositivo hispanista”, en Actas del III Congreso Argentino de Hispanistas "España en América y América en España”: Buenos Aires, Argentina, 19, 20, 21, 22 y 23 de mayo de 1992 / coord. por Luis Martínez Cuitiño, Elida Lois, Vol. 1, 1993.

VIDAL DE BATTINI, Berta Elena, "El folklore en la escuela”, en El monitor de la educación común, Buenos Aires: a. LI, nr. 715, 1932.

ZUMTHOR, Paul. La letra y la voz. Trad. Julián Presa. Madrid: Cátedra, 1989. . Escritura e nomadismo. Trad. Jesusa Pires Ferreira; Sonia Quiroz. Sao Paulo: Atelié Editorial, 2005. 